\title{
The macroeconomic impact of pandemic influenza: estimates from models of the United Kingdom, France, Belgium and The Netherlands
}

\author{
Marcus Richard Keogh-Brown • Richard D. Smith • \\ John W. Edmunds · Philippe Beutels
}

Received: 21 January 2009/Accepted: 17 November 2009/Published online: 9 December 2009

(C) Springer-Verlag 2009

\begin{abstract}
The 2003 outbreak of severe acute respiratory syndrome (SARS) showed that infectious disease outbreaks can have notable macroeconomic impacts. The current H1N1 and potential H5N1 flu pandemics could have a much greater impact. Using a multi-sector single country computable general equilibrium model of the United Kingdom, France, Belgium and The Netherlands, together with disease scenarios of varying severity, we examine the potential economic cost of a modern pandemic. Policies of school closure, vaccination and antivirals, together with prophylactic absence from work are evaluated and their cost impacts are estimated. Results suggest GDP losses from the disease of approximately $0.5-2 \%$ but school closure and prophylactic absenteeism more than triples these effects. Increasing school closures from 4 weeks at the peak to entire pandemic closure almost doubles the economic cost, but antivirals and vaccinations seem worthwhile. Careful planning is therefore important to ensure expensive policies to mitigate the pandemic are effective in minimising illness and deaths.
\end{abstract}

\footnotetext{
M. R. Keogh-Brown $(\bowtie) \cdot$ R. D. Smith

Health Policy Unit, Department of Public Health and Policy, London School of Hygiene and Tropical Medicine,

Keppel Street, WC1E 7HT London, UK

e-mail: Marcus.keogh-brown@1shtm.ac.uk

\section{J. W. Edmunds}

Department of Infectious and Tropical Diseases, London School of Hygiene and Tropical Medicine, Keppel Street, WC1E 7HT London, UK

\section{P. Beutels}

Centre for Health Economics Research and Modelling Infectious Diseases (CHERMID), Vaccine and Infectious Disease Institute, University of Antwerp, Campus Drie Eiken, Universiteitsplein 1, 2610 Antwerpen, Belgium
}

Keywords Macroeconomic modelling · Influenza · Computable general equilibrium

JEL Classification D58

\section{Introduction}

The outbreak of severe acute respiratory syndrome (SARS) in 2003 highlighted the importance for countries of making appropriate preparations for possible future infectious disease outbreaks [1]. An influenza pandemic had been anticipated prior to 2009 since there were three influenza pandemics in the twentieth century, the most recent occurring in 1968. Now the world is undergoing a pandemic and there are fears that the currently mild H1N1 swine flu might precipitate a more deadly strain of influenza either later this year or in the near future. In addition to this, the current pandemic has not removed the threat of a more virulent avian flu pandemic in the near future. From this infectious disease precipice the importance of pandemic planning is plain. Most countries have already published influenza pandemic preparedness plans and many have invested in antivirals [2]. However, none of these plans have an adequate economic component for estimating the likely cost of a pandemic, the benefits of policies to mitigate disease effects, or the distribution of these costs and benefits within the economy [3].

Whilst it is important that appropriate measures are taken to minimise the mortality and morbidity associated with a pandemic, these measures can be costly: a more widespread pandemic would be more costly than SARS [1]. Further, in the case of an infectious disease outbreak, as illustrated by SARS, the impact will be disproportionately spread across sectors in the economy, which may 
influence policy (e.g. loans and subsidies). It would therefore be beneficial to estimate the cost of the disease itself, the distribution of this cost across sectors, and the cost of policies that may be used to mitigate the pandemic. It is hoped that, by this method, economic analysis can better help inform pandemic preparedness policies.

This paper concerns an application of a single country computable general equilibrium (CGE) model, together with epidemiological data, to estimate the prospective impact to several economies of an influenza pandemic. Whilst these estimates are not intended to be taken as definitive values of future pandemic costs, in conjunction with other findings they enable verification of which policies are of greatest importance in the consideration of future pandemic costs. They also allow an examination of sectors that might be expected to exhibit a notable response to the outbreak. The disease scenarios considered involve a basic pandemic disease scenario, similar to the pandemics of 1957 and 1968/1969, as well as a more severe 1918-like pandemic scenario. Against the background of these disease scenarios, the additional costs of controlling the disease, including school closures over various time periods and prophylactic absenteeism of both 1 and 4 weeks duration, are assessed.

Since our model estimates the whole economy impact of influenza it stands in contrast to the partial equilibrium study by Sander et al. [4], where a microeconomic approach to cost-utility estimation is used, together with an infection model, to estimate the cost of disease and mitigation strategies for pandemic influenza in the United States. Sander et al. estimate costs by simulating disease spread, capturing individual costs based on the human capital approach and estimating the compensation of lost working time, together with medical costs that include complications. Mitigation strategies including school closure, various antiviral prophylaxis strategies (both household and household plus work/school contacts) and pre-pandemic vaccination are used to influence the severity of the pandemic. Sander's study therefore uses a direct method of cost estimation calculated from the individual level. Our modelling approach is entirely different. We use a whole economy model and impose aggregate shocks representing labour supply impacts attributable to illness and absenteeism. As a result of the fall in labour supply, productivity is affected, which changes prices, preferences and consumption patterns and these behaviours are captured and used to estimate the change throughout the economy with sectoral level detail from which the overall impact of the pandemic can be estimated. Our impacts are not therefore confined to the health sector or to the individuals who are directly affected, as commented on in [3], but encapsulate all sectors to provide an aggregate picture for the entire economy of a country.

\section{Methods}

\section{Modelling a pandemic}

In order to estimate the macroeconomic cost of pandemic influenza, the main disease parameters of interest are deaths (which have a permanent impact on the working population) and absenteeism (which temporarily impacts the working population through illness). Illness-related absenteeism and deaths can be estimated via the clinical attack rate (CAR) and the case fatality ratio (CFR) of the disease, respectively. The CAR expresses the number of people who become ill, and the CFR expresses the proportion of infected individuals who die from influenza.

In order to estimate the CFR of a future pandemic, the properties of past pandemics are considered, which varied from $0.04 \%$ for the working population in $1958 / 1969$ to 2.5\% in 1918 as outlined in the United Kingdom (UK)Department of Health pandemic influenza plan [5].

Clinical attack rates of $>30 \%$ were recorded for the 1957 pandemic [6] and estimates of $>45 \%$ were recorded in 1968/1969 [7]. In these two pandemics the clinical attack rates appear to have been highest in children, whereas the highest recorded incidence in the 1918 pandemic was in young adults [8]. For the scenarios here, a CAR of $35 \%$ is applied to the basic disease scenario [5], and a severe disease scenario with a CAR value of $50 \%$ is also considered, which would result in a further increase in deaths (as the percentage of the population that dies is simply the CAR*CFR). This upper boundary on CAR is based on previous data [7] and is also suggested as an upper limit in some pandemic preparedness plans $[5,9-12]$.

\section{Policies/behavioural change}

Two policies are considered, both of which are intended to mitigate the impact of the disease, but conversely increase the absenteeism rate in the working population and therefore the potential economic cost. First, school closures of 4 and 13 weeks to mitigate disease spread at the peak or throughout the pandemic, respectively. These closures will impact on working parents who are responsible for dependent children. The estimate of this impact is based on the UK Labour Force Survey (2005; http://www.dataarchive.ac.uk/), which suggests that there are a total of 25,245,000 individuals aged 16-64 who are in paid employment. Of these, 3,900,000 are women who are either the head of the household or the spouse of, or cohabiting with, the head of the household and have dependent children in the household $<16$ years of age. That is, $15.5 \%$ of the workforce comprises women who are probably responsible for dependent children [13] and this 
percentage of the labour supply will therefore be removed from the economy during the weeks of school closure. This assumption does not account for the fact that some parents will continue to work despite having children at home during the pandemic. Our estimate is therefore likely to be an over-estimate of absenteeism, but there is insufficient evidence to estimate an alternative.

The second policy is prophylactic absenteeism. Whilst this could be instigated by government advice, it is more likely that individuals will remove themselves from work of their own volition in an attempt to avoid infection. Some of the authors were involved in a study to estimate the risk perception and behaviour of individuals [13] and the results of this survey from European respondents suggest that $34 \%$ of workers would take prophylactic absenteeism in the event of an influenza pandemic, of which $3.75 \%$ were women who had children at school and would therefore overlap with the school closure absenteeism. However, the remaining $30 \%$ represent the additional shock due to prophylactic absenteeism. It should be highlighted that there is some uncertainty as to whether individuals who state an intention to take prophylactic absenteeism would, in reality, carry out this intention, so this shock should be seen as a worst case scenario.

Feedback effects on disease epidemiology

School closure and prophylactic absence are likely to impact the progression of the pandemic. Ferguson et al. [14] estimate the impact of school closure and absence from work on mitigating an influenza pandemic. A $34 \%$ CAR is assumed in the absence of mitigation strategies, which is similar to our base CAR of $35 \%$, and school closure (closing $100 \%$ of schools and $10 \%$ of workplaces) from the day after the first case in pupils or staff is detected until 3 weeks after the last case in the school) is estimated to reduce the CAR by $2 \%$. This mitigation action is most closely related to our scenario policy with 13 weeks of school closure. For our 35\% CAR scenarios we therefore assume a $2 \%$ reduction in CAR for 13 weeks of school closure and one-quarter of this effect $(0.5 \%$ reduction) for the 4-week school closure policy. For the $50 \%$ CAR scenarios we scale the 13- and 4-week closure impacts up to $3 \%$ and $0.75 \%$ reductions, respectively. Ferguson et al. [14] also show that if 50\% of workplaces close, an additional $1 \%$ reduction in CAR is achieved. We liken this scenario to our longer (4 week) prophylactic absence scenario (although this involves removal of only $34 \%$ of workers) and assume a $1 \%$ reduction in the $35 \%$ CAR for 4 weeks of prophylactic absence and one-quarter $(0.25 \%)$ for 1 week of prophylactic absence. These impacts are scaled up to 1.5 and $0.38 \%$ reductions for the $50 \%$ CAR scenarios.

\section{Antivirals/vaccinations}

In addition to the school closure and prophylactic absence scenarios we also consider antiviral and vaccine strategies. We assume that antivirals are given after 24 hours and that coverage is $66 \%$ (the remaining $34 \%$ are assumed to receive antivirals too late for them to be effective). We also assume that antivirals reduce infectiousness by $66 \%$ and hospitals and deaths by $60 \%$. The vaccine strategy we model assumes a prepandemic, immunising vaccine with $25 \%$ efficacy and $80 \%$ coverage (all ages).

The pandemic scenarios generated from combinations of the above policies and disease parameters are summarised in Tables 1 and 2.

The model

The model is based on the Ecomod one-country CGE model, as used in previous analyses [15]. It uses the standard microeconomic theory underlying many such models including [16-18] and is a single-country CGE open economy model consisting of 11 sectors. Although the model is a single-country model, it is an open-economy model, meaning that foreign trade is captured through imports and exports. This means that commodities and their prices differ with regard to origin and destination. The differences between origins are encapsulated as follows. Domestically produced commodities are sold both in the domestic market and abroad. Sales abroad take the form of exports and are modelled using a constant elasticity of transformation (CET) function. ${ }^{1}$ Domestic sales originate from domestic and foreign sources (imports) and this is modelled using a composite commodity and Armington assumption. ${ }^{2}$ Composite commodities can then be used as an input into the production process of the domestically produced commodities or sold for final consumption by households, government or domestic investment.

There are also differences with regard to the pricing of commodities. In the model the domestic price of commodities is parameterised, as is the import price in the currency of the world market and the export price. In order to enable domestic prices to be transformed into currency on the world market an exchange rate is also parameterised.

CGE modelling also produces the welfare measure of equivalent variation (EV), which represents the amount of money that, if an economic change does not happen, leaves

\footnotetext{
${ }^{1}$ A CET function determines how the domestically produced commodity is allocated between the domestic market and exports. A constant value for this elasticity is set for each sector.

2 The Armington assumption determines the way in which the domestically produced commodity and imports are combined into a composite commodity by means of an elasticity of substitution. This elasticity is constant for each sector.
} 
Table 1 Influenza (flu) scenarios for disease only and increased case fatality ratio (CFR). $P A$ Prophylactic absence, $S C$ school closure

\begin{tabular}{|c|c|c|c|c|c|c|}
\hline & $\begin{array}{l}\text { Clinical attack rate } \\
\text { (\% working population) }\end{array}$ & CFR & $\begin{array}{l}\text { Working population } \\
\text { mortality rate }(\%)\end{array}$ & $\begin{array}{l}\text { Working days lost } \\
\text { due to illness }\end{array}$ & $\begin{array}{l}\text { School closure } \\
\text { (weeks) }\end{array}$ & $\begin{array}{l}\text { Prophylactic } \\
\text { absenteeism (weeks) }\end{array}$ \\
\hline \multicolumn{7}{|l|}{ Mild flu } \\
\hline Illness & 35 & 0.04 & 0.014 & 5 & 0 & 0 \\
\hline PA1 & 34.75 & 0.04 & 0.0139 & 5 & 0 & 1 \\
\hline $\mathrm{SC} 4$ & 34.5 & 0.04 & 0.0138 & 5 & 4 & 0 \\
\hline PA1 and SC4 & 34.25 & 0.04 & 0.0137 & 5 & 4 & 1 \\
\hline PA4 & 34 & 0.04 & 0.0136 & 5 & 0 & 4 \\
\hline SC13 & 33 & 0.04 & 0.0132 & 5 & 13 & 0 \\
\hline ALL & 32 & 0.04 & 0.0128 & 5 & 13 & 4 \\
\hline \multicolumn{7}{|l|}{ High CFR } \\
\hline Illness & 35 & 2.5 & 0.875 & 5 & 0 & 0 \\
\hline SC4 & 34.5 & 2.5 & 0.8625 & 5 & 4 & 0 \\
\hline PA4 & 34 & 2.5 & 0.85 & 5 & 0 & 4 \\
\hline SC13 & 33 & 2.5 & 0.825 & 5 & 13 & 0 \\
\hline ALL & 32 & 2.5 & 0.8 & 5 & 13 & 4 \\
\hline
\end{tabular}

Table 2 Flu scenarios for increased clinical attack rate (CAR) and severe disease. Antivirals (AV) and vaccines

\begin{tabular}{|c|c|c|c|c|c|c|}
\hline & $\begin{array}{l}\text { CAR } \\
\text { (\% working } \\
\text { population) }\end{array}$ & CFR & $\begin{array}{l}\text { Working } \\
\text { population } \\
\text { mortality rate \% }\end{array}$ & $\begin{array}{l}\text { Working } \\
\text { days lost } \\
\text { due to illness }\end{array}$ & $\begin{array}{l}\text { School } \\
\text { closure } \\
\text { (weeks) }\end{array}$ & $\begin{array}{l}\text { Prophylactic } \\
\text { absenteeism } \\
\text { (weeks) }\end{array}$ \\
\hline \multicolumn{7}{|l|}{ High CAR } \\
\hline Illness & 50 & 0.04 & 0.02 & 5 & 0 & 0 \\
\hline $\mathrm{SC} 4$ & 49.25 & 0.04 & 0.0197 & 5 & 4 & 0 \\
\hline PA4 & 48.5 & 0.04 & 0.0194 & 5 & 0 & 4 \\
\hline $\mathrm{SC} 13$ & 47 & 0.04 & 0.0188 & 5 & 13 & 0 \\
\hline ALL & 45.5 & 0.04 & 0.0182 & 5 & 13 & 4 \\
\hline \multicolumn{7}{|l|}{ Severe } \\
\hline Illness & 50 & 2.5 & 1.25 & 7 & 0 & 0 \\
\hline $\mathrm{SC} 4$ & 49.25 & 2.5 & 1.23125 & 7 & 4 & 0 \\
\hline PA4 & 48.5 & 2.5 & 1.2125 & 7 & 0 & 4 \\
\hline SC13 & 47 & 2.5 & 1.175 & 7 & 13 & 0 \\
\hline ALL & 45.5 & 2.5 & 1.1375 & 7 & 13 & 4 \\
\hline \multicolumn{7}{|l|}{ Antivirals and vaccines } \\
\hline Base with AV (+SC) & 27.5 & 0.02 & 0.0055 & 4.29 & 4 & 0 \\
\hline Severe with AV (+SC) & 33 & 1.5 & 0.495 & 6.27 & 13 & 0 \\
\hline Base with vaccine $(+\mathrm{SC})$ & 19.5 & 0.02 & 0.0039 & 5 & 4 & 0 \\
\hline Severe with vaccine $(+\mathrm{SC})$ & 24 & 1.5 & 0.36 & 7 & 13 & 0 \\
\hline Base with vaccine AV $(+\mathrm{SC})$ & 15.5 & 0.01 & 0.00155 & 4.29 & 4 & 0 \\
\hline Severe with vaccine, AV $(+\mathrm{SC})$ & 17 & 0.9 & 0.153 & 6.27 & 13 & 0 \\
\hline
\end{tabular}

the individual just as well off as if the change had occurred. This may be thought of as the amount of money that society might be willing to pay to avert the change [19, 20]. For the purposes of this paper, the welfare measure $(\mathrm{EV})$ is quoted as a percentage of GDP.

\section{Countries and data}

The data underlying the model take the form of a social accounting matrix (SAM) generated from input output tables of the countries concerned: the UK, France, Belgium 
and The Netherlands, for the year 2000, except for the UK, which was 2003. These countries were specified for the modelling application by the SARSControl Research Project, which funded this research. For each country, the input-output table data has been aggregated into 11 sectors:

- Agriculture

- Retail

- Hotels and restaurants

- Freight and public transport

- Tourism and travel

- Post and telecommunications

- Insurance

- Education

- Health and social work

- Non-essential items

- Other

Further details on the aggregation of these sectors is provided in the Appendix.

In addition to the SAM underlying the model, elasticity parameters for substitution in the CET and Armington functions were also calculated [21].

\section{Results}

Figure 1 shows the impact on GDP of the mild and the most severe disease scenarios specified in Tables 1 and 2 for all four countries. Focussing on UK values, the loss due to disease only is $0.48 \%$, the 1 week prophylactic absenteeism effect is twice as large $(0.94 \%)$, the school closure scenario yields an impact of $1.32 \%, 1$ week of prophylactic absenteeism combined with 4 weeks of school closure yields a GDP loss of $1.72 \%$, 4 weeks of prophylactic absenteeism yields a loss of $2.32 \%$ which, in order to place these impacts in context, is also the reduction in UK GDP

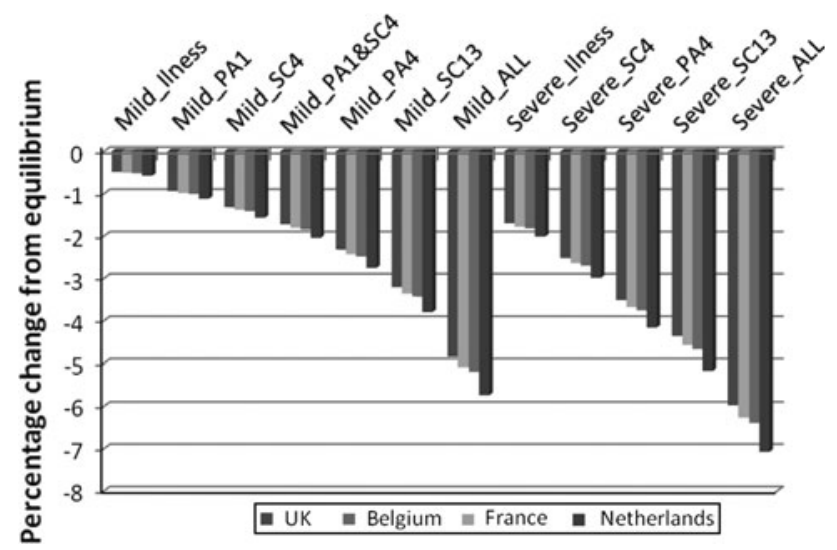

Fig. 1 Gross domestic product (GDP) for disease and severe disease by country due to the current recession thus far. Thirteen weeks of school closure yields $3.2 \%$, and combining the 4 weeks of prophylactic absenteeism with 13 weeks of school closure yields a loss of $4.85 \%$. The plot shows that there is a pattern across countries with regard to GDP impact: the smallest effect is exhibited for the UK, France has proportional impacts for each scenario, but the magnitude of those impacts is greater than the UK by a factor of 0.05 , Belgium and the Netherlands also exhibit impacts proportional to those of the UK but are greater than the UK impacts by a factor of 0.07 and 0.19 , respectively. One explanation for this might be the proportionally higher exports in those countries compared with the UK; since exports are adversely affected by the influenza shock (Fig. 4) the overall impact is slightly larger in those other countries.

Since the pattern of losses for scenarios is similar across countries, discussion focuses on UK GDP losses as plotted in Fig. 2. It can be seen that as the severity of disease increases, the increased losses to GDP are relatively minor; the increased CAR scenarios yield an increased loss to GDP of approximately $0.21 \%$ over their corresponding base disease counterparts, the increased CFR scenarios yield a $0.51 \%$ greater loss to GDP than base disease and the severe disease scenarios yield increases of approximately $1.22 \%$ over the base disease scenarios. These losses are smaller than those highlighted above for the introduction of school closure and prophylactic absenteeism and are further demonstrated in Fig. 2, which clearly shows a greater change in GDP loss for changes in behaviour/policy than for changes in disease alone.

In Fig. 3 the impacts on domestic output to the domestic market are viewed from a sectoral perspective; the sectoral impacts are calculated within the model using the SAM inputs and elasticities rather than by sector-specific shocks. For all countries, the plots display a general decline from left to right, with agriculture exhibiting the smallest impact and the larger impacts accruing to education, health and social services, non-essentials and other. The plots for

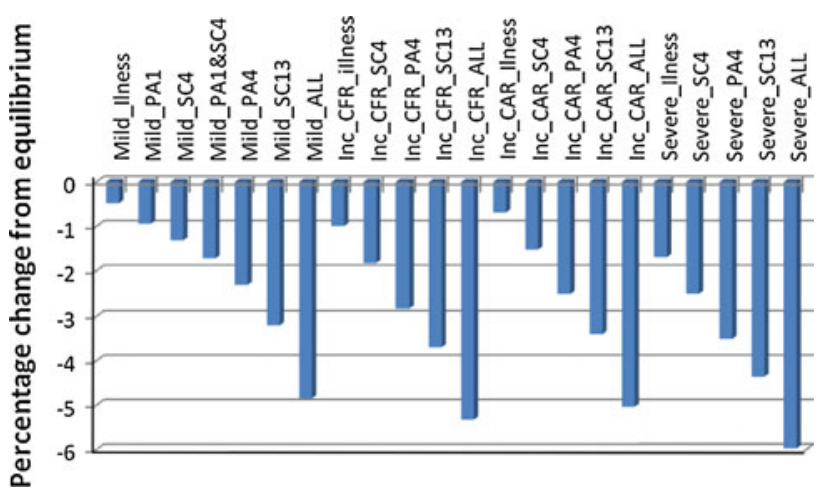

Fig. 2 United Kingdom GDP loss 

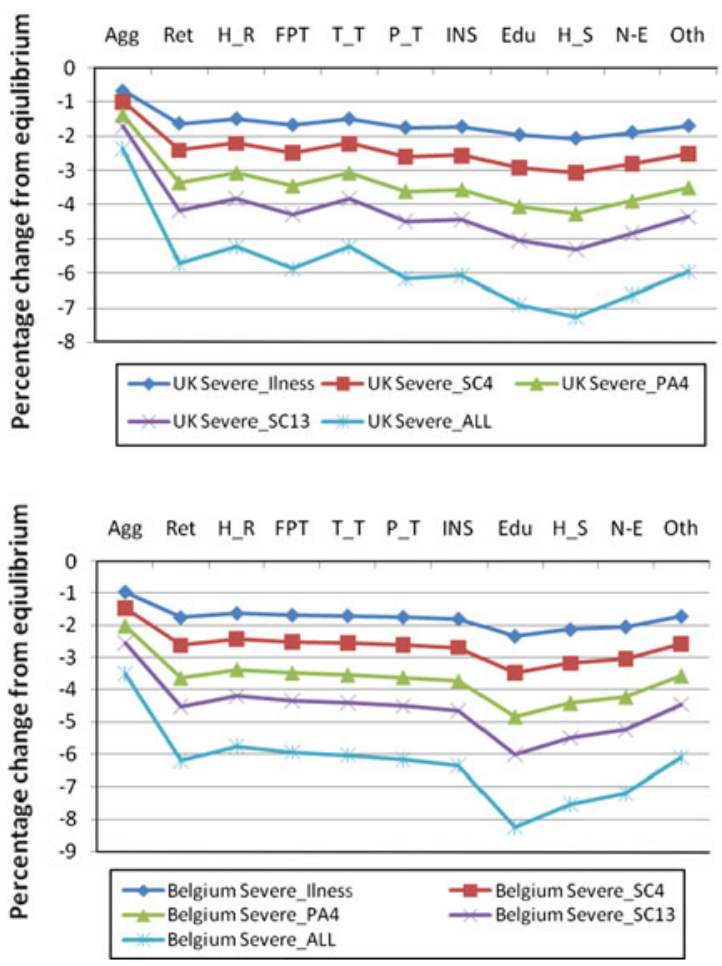

Fig. 3 Domestic output to home market by sector and country

France and Belgium are very similar, with the smallest impact occurring for agriculture. Retail has a larger impact, which is similar to that of the insurance sector and other services, hotels and restaurants, freight and public transport, transport and tourism, and post and telecommunications exhibit losses between those of agriculture and retail. Education receives the largest shock, followed by health and social services and non-essentials.

The UK has similar results, but differences in the UK economy have resulted in a smaller impact on agriculture. Hotels and restaurants, together with transport and tourism, have the next smallest impacts, followed by retail, freight and public transport, post and telecommunications, insurance and other, all of which exhibit similar impacts. Education, together with non-essentials, has the next largest impact and the most impacted sector in the UK seems to be the health sector.

The impacts on the Netherlands for the first seven plotted sectors are similar to those of France and Belgium. Agriculture receives the smallest (almost zero) impact; retail, hotels and restaurants, freight and public transport, post and telecommunications and other exhibit similar values to the other countries; but education, health and social services, and non-essentials have almost twice as large a loss as the other sectors, with non-essentials receiving the largest impact.

Plots of imports and exports by sector are shown in Figs. 4 and 5, respectively. All countries show the largest
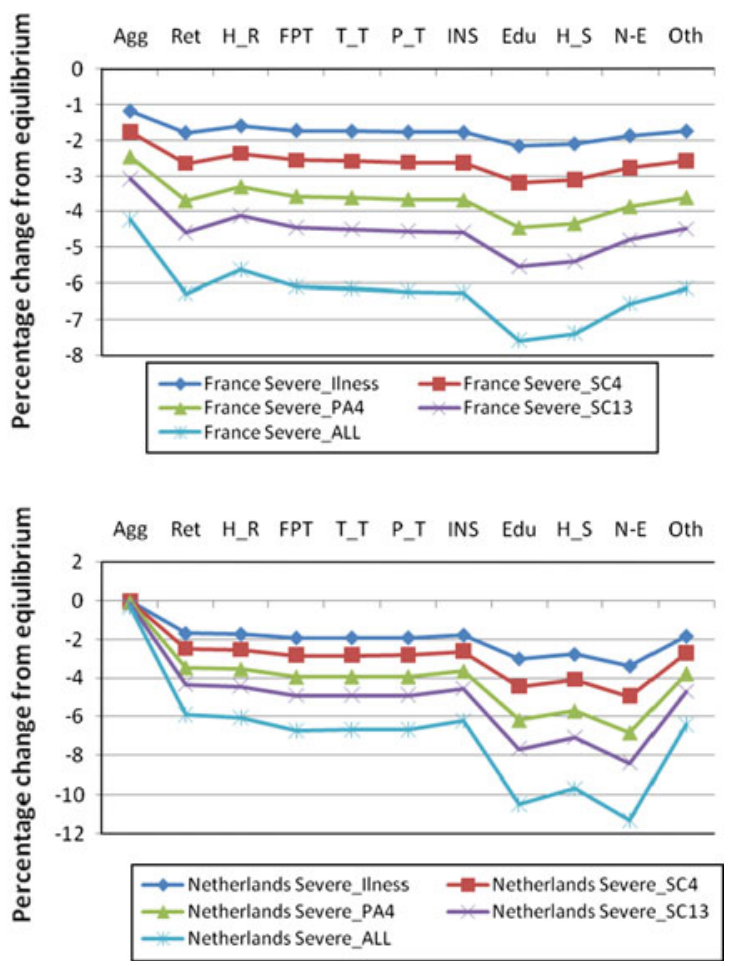

loss of exports in the agriculture sector, although this impact is particularly large in the Netherlands. For the UK, the transport and tourism sector receive larger impacts than the other sectors, and non-essentials receive the smallest impact. The other sectors exhibit a similar impact to one another. France and Belgium's exports receive a similar impact across all sectors except agriculture. The Netherlands' exports exhibit a large impact to freight and public transport, whilst other sectors exhibit smaller values. Import effects similarly show the largest impact on agriculture for all countries except the UK, for which transport and tourism suffers the largest loss. Again, the impact on the Netherlands agriculture is large. France and Belgium imports have a fairly flat effect across all sectors except agriculture, but the Netherlands suffers proportionally large impacts to freight and public transport, education and health and social services. The least impacted sector in the Netherlands is non-essentials.

Domestic consumption is plotted in Fig. 6. The countries exhibit similar loss patterns across sectors, with agriculture receiving very little fall in consumption; the impacts on the other sectors are fairly similar.

\section{Antivirals/vaccinations}

Figure 7 shows the impact of the antiviral, vaccination and combined antiviral and vaccination strategies we modelled. Antivirals are estimated to reduce the impact on GDP by 

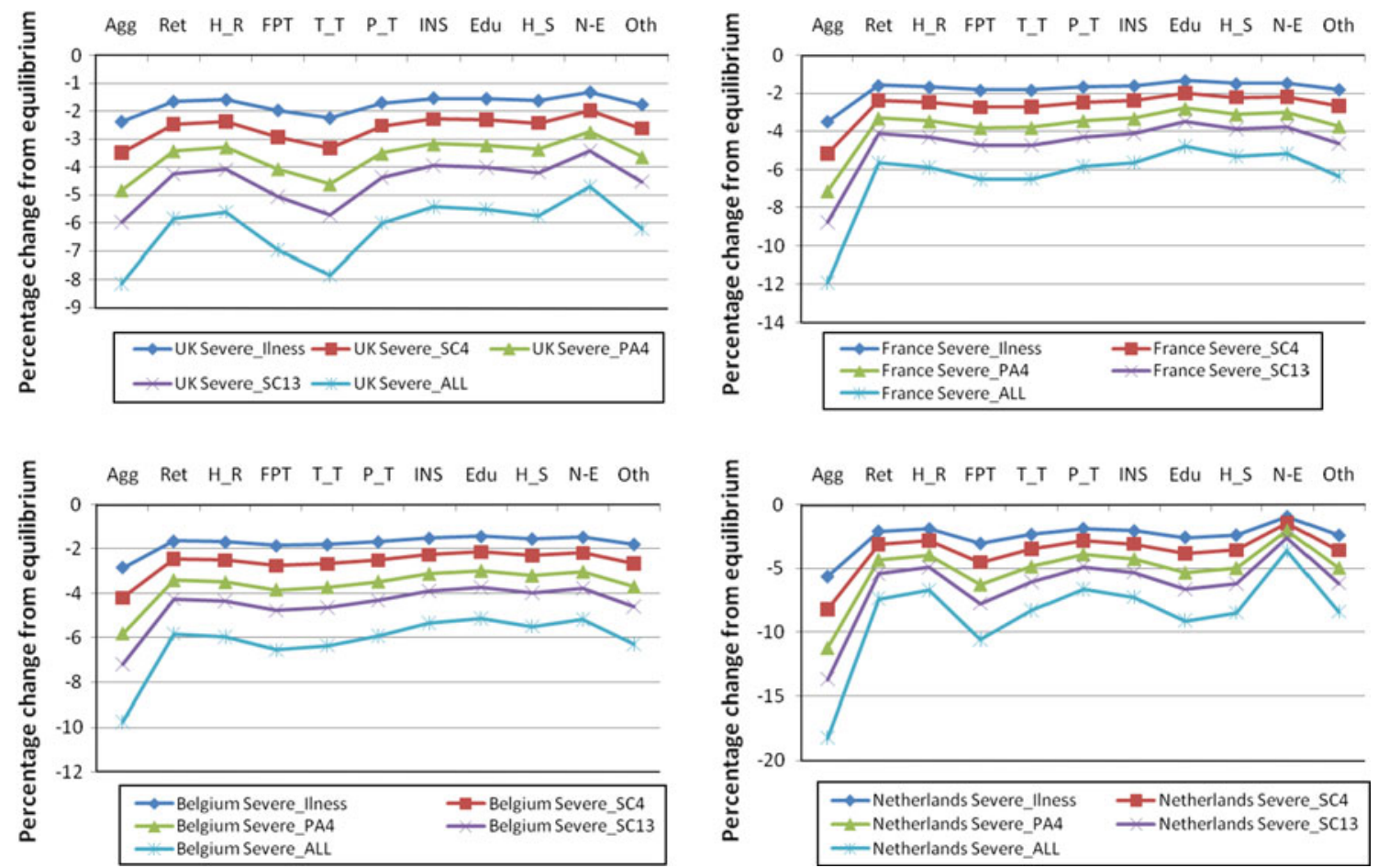

Fig. 4 Exports by sector and country
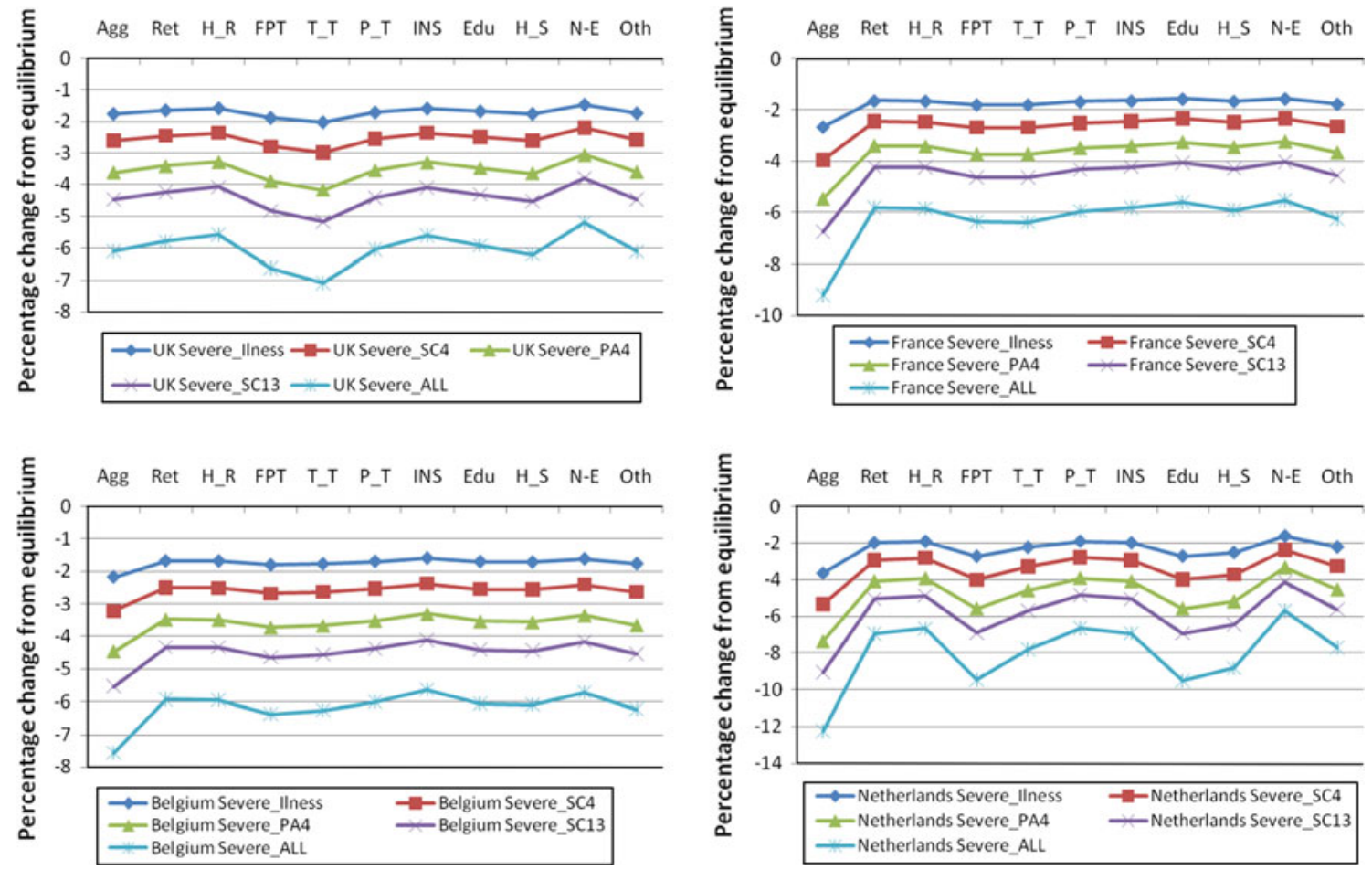

Fig. 5 Imports by country and sector

$0.15 \%$ for a mild flu scenario with 4 weeks school closure and $0.75 \%$ for a more severe flu scenario with 13 weeks of school closure. The equivalent savings of vaccinations are $0.21 \%$ and $0.94 \%$ for the mild and severe scenarios,

respectively, and the savings of the combined strategy are $0.3 \%$ for a mild pandemic and $1.23 \%$ for a severe pandemic; similar savings could be achieved in the other countries modelled. For the UK intervention strategy, these 

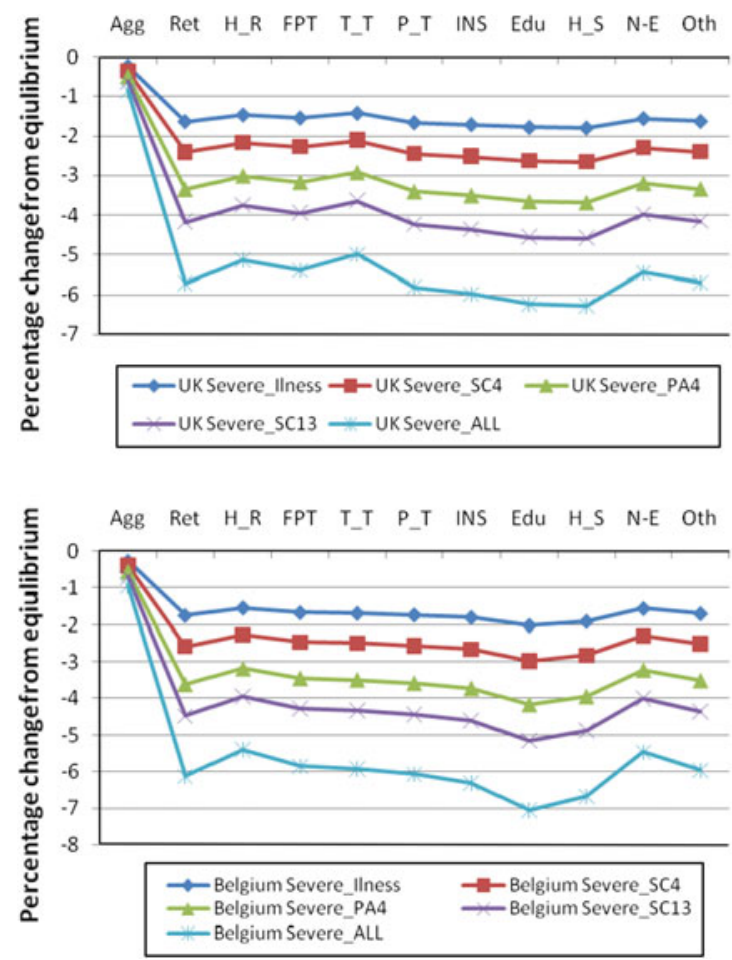

Fig. 6 Household consumption by country and sector

savings equate to $£ 4.1 \mathrm{bn}, £ 5.7 \mathrm{bn}, £ 8.0 \mathrm{bn}$, respectively for the antiviral, vaccination and combined strategy in a mild pandemic, and $£ 20.2 \mathrm{bn} £ 25.3 \mathrm{bn}$ and $£ 33$.3bn for the severe pandemic. The approximate costs of the antiviral and vaccine strategies is $0.75 \mathrm{bn}$ and $0.85 \mathrm{bn}$, respectively, suggesting that such an intervention would be worthwhile.

EV results, quoted as a percentage of GDP, are presented in Table 3. For the UK, these results range from $0.37 \%$ for the mild disease only scenario up to $4.985 \%$ for the most severe, suggesting that society would be willing to pay some $£ 10$ bn to $£ 131$ bn to avert the economic impact of the pandemic. Impacts on the other three countries are slightly smaller, but it should be highlighted that these estimates do not include society's willingness to pay to avoid the illness and possible death that accompany pandemic influenza.

\section{Discussion}

This paper has presented the results of both main economic indicators and sectors for a single country CGE model of the UK, France, Belgium and the Netherlands. The constitution of these countries' economies results in slightly different impacts, with GDP impacts being largest for the Netherlands, followed by Belgium, France and the UK. In terms of domestic output to the domestic economy, the Netherlands suffers due to the essential commodities of
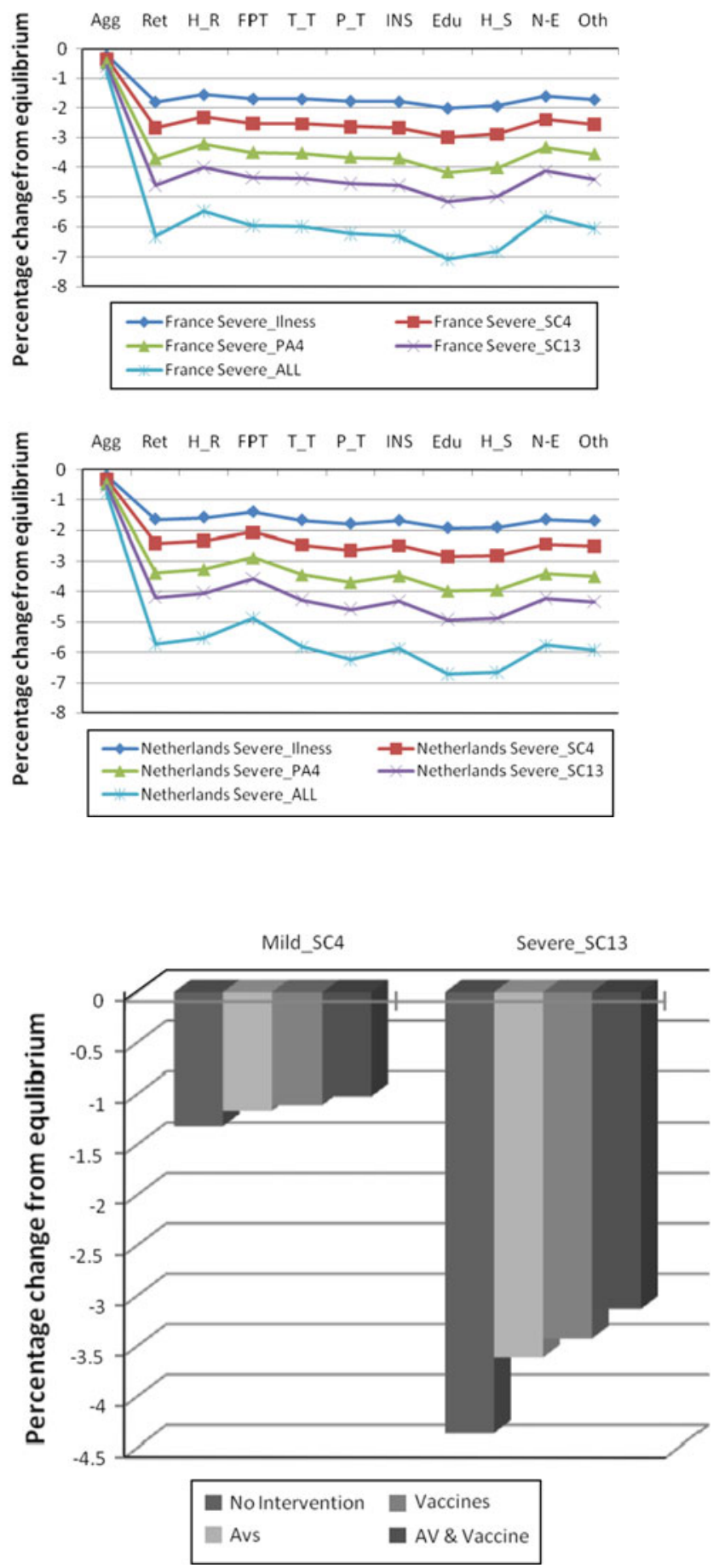

Fig. 7 Impact of antivirals, vaccination and combination treatment on GDP

agriculture at the expense of its agriculture imports and exports, but education, health and social services, and nonessentials have much larger domestic output losses; the UK similarly displays very small agriculture impacts; its imports and exports do not suffer as much as the Netherlands but the UK experiences large impacts to the health sector. In general, whilst there are slight differences 
Table 3 Equivalent variation as a percentage of GDP. EV Equivalent variation

\begin{tabular}{|c|c|c|c|c|}
\hline & $\begin{array}{l}\text { United Kingdom EV } \\
\text { (\% of GDP) }\end{array}$ & $\begin{array}{l}\text { France EV } \\
\text { (\% of GDP) }\end{array}$ & $\begin{array}{l}\text { Belgium EV } \\
\text { (\% of GDP) }\end{array}$ & $\begin{array}{l}\text { The Netherlands EV } \\
\text { (\% of GDP) }\end{array}$ \\
\hline Mild_illness & -0.37 & -0.29 & -0.28 & -0.25 \\
\hline Mild_PA1 & -0.73 & -0.57 & -0.55 & -0.48 \\
\hline Mild_SC4 & -1.02 & -0.80 & -0.77 & -0.68 \\
\hline Mild_PA1 \& SC4 & -1.34 & -1.05 & -1.01 & -0.89 \\
\hline Mild_PA4 & -1.81 & -1.42 & -1.37 & -1.21 \\
\hline Mild_SC13 & -2.53 & -1.98 & -1.91 & -1.69 \\
\hline Mild_ALL & -3.89 & -3.05 & -2.95 & -2.60 \\
\hline Inc_CFR_illness & -0.77 & -0.60 & -0.58 & -0.51 \\
\hline Inc_CFR_SC4 & -1.42 & -1.11 & -1.08 & -0.95 \\
\hline Inc_CFR_PA4 & -2.22 & -1.74 & -1.68 & -1.48 \\
\hline Inc_CFR_SC13 & -2.93 & -2.30 & -2.22 & -1.96 \\
\hline Inc_CFR_ALL & -4.30 & -3.37 & -3.26 & -2.87 \\
\hline Inc_CAR_illness & -0.53 & -0.42 & -0.40 & -0.35 \\
\hline Inc_CAR_SC4 & -1.18 & -0.93 & -0.89 & -0.78 \\
\hline Inc_CAR_PA4 & -1.98 & -1.55 & -1.50 & -1.32 \\
\hline Inc_CAR_SC13 & -2.69 & -2.11 & -2.04 & -1.79 \\
\hline Inc_CAR_ALL & -4.05 & -3.18 & -3.07 & -2.71 \\
\hline Severe_illness & -1.32 & -1.03 & -1.00 & -0.88 \\
\hline Severe_SC4 & -1.97 & -1.55 & -1.49 & -1.31 \\
\hline Severe_PA4 & -2.78 & -2.18 & -2.10 & -1.85 \\
\hline Severe_SC13 & -3.48 & -2.73 & -2.64 & -2.33 \\
\hline Severe_ALL & -4.85 & -3.81 & -3.68 & -3.25 \\
\hline Base + AV \& SC & -0.90 & -0.71 & -0.68 & -0.60 \\
\hline Severe + AV \& SC & -2.86 & -2.24 & -2.17 & -1.91 \\
\hline Base + vaccine $\&$ SC & -0.86 & -0.67 & -0.65 & -0.57 \\
\hline Severe + vaccine $\&$ SC & -2.71 & -2.12 & -2.05 & -1.80 \\
\hline Base + vaccine AV \& SC & -0.79 & -0.62 & -0.60 & -0.52 \\
\hline Severe + vaccine AV \& SC & -2.47 & -1.93 & -1.87 & -1.64 \\
\hline
\end{tabular}

between countries, the country results are quite similar, with France and Belgium in particular showing very similar impacts to each other. Overall, the economic impacts of the disease itself, despite the large number of infections and deaths, is likely to be small: between $0.5 \%$ of GDP for a mild pandemic to just over $2 \%$ for a severe pandemic. However, the model suggests that the main factors influencing the size of the economic impact are behavioural changes to avoid infection, such as prophylactic absenteeism and policies such as school closure. This is not to suggest that the economic impact should take precedence over saving lives and reducing infections when determining policy, but that the potential effectiveness of policies should be weighed against their economic impact. For example, based on these results, the difference between closing schools for the peak of the pandemic (4 weeks) versus closing them for the entire pandemic (13 weeks) would cost the UK an estimated $£ 27$ billion and might double the cost of the pandemic. It might therefore be advisable to consider the cost-effectiveness of such a policy before it is implemented.

Prophylactic absenteeism could also be costly. However, as already mentioned, it is possible that the estimates of prophylactic absenteeism used may not be realised in practice. However, publicising the lack of effectiveness of prophylactic absenteeism to discourage such absence might be worthwhile.

Sectoral impacts suggest that labour intensive sectors such as insurance, health and social services and education receive large losses to domestic output, whilst agriculture is the least affected sector across all countries. Imports and exports exhibit quite different effects from those of domestic output; it would seem that agriculture, whilst maintaining its output to the domestic market suffers the largest losses in imports and exports. France and Belgium exhibit similar sectoral effects, with less distinction between sector losses, whereas the UK and the Netherlands show greater variation between sectoral losses. Further development on this model 
to accommodate sector-specific shocks that reflect changes in consumer behaviour towards those sectors during a pandemic would also be beneficial.

There is some evidence to suggest that vaccinations, antivirals or a combined strategy of both antivirals and vaccines could be a cost-effective intervention, and this evidence does not fully take into account the additional benefits of lives saved from these strategies.

The welfare measures also show that, particularly for the severe scenarios, there is potentially a high societal willingness to pay in order to avert the economic changes attributable to the pandemic. It would therefore seem that investment in appropriate strategies, such as vaccines and antivirals, to mitigate the cost of the pandemic is justified, provided that those strategies are effective in reducing the impact of the disease.

Whilst these results do not provide definitive estimates of the cost of a future influenza pandemic, they do highlight the fact that the economy is highly sensitive to the strategies and policies that are implemented in response to a pandemic. This suggests that a very careful balance must be found to minimise death and disease whilst ensuring that strategies used are not only justified by their effectiveness but also carefully measured in their implementation. Whilst our results provide a helpful indication for the implementation of school closure and the cost of prophylactic absenteeism, further analysis is necessary in order to inform policy makers whose decisions may have marked effects on the economies of the world.

Acknowledgement This work was conducted as part of "SARSControl: Effective and acceptable strategies for the control of SARS and new emerging infections in China and Europe", a European Commission project funded within the Sixth Framework Programme, Thematic Priority Scientific Support to Policies, Contract number: SP22-CT-2004-003824.

\section{Appendix}

Symmetric input-output (IO) tables aggregation

Agriculture

- Products of agriculture, hunting and related services

Retail

- Retail trade services, except of motor vehicles and motorcycles; repair services of personal and household goods

Hotels and Restaurants

- Hotel and restaurant services

Freight and Public Transport
- Land transport; transport via pipeline services

Tourism and Travel

- Water transport services

- Air transport services

- Supporting and auxiliary transport services; travel agency services

Post and Telecom

- Post and telecommunication services

Insurance

- Insurance and pension funding services, except compulsory social security services

Education

- Education services

Health and Social Work

- Health and social work services

Non-Essential Items

- Wearing apparel; furs

- Leather and leather products

- Machinery and equipment not elsewhere classified (n.e.c.)

- Office machinery and computers

- Electrical machinery and apparatus n.e.c.

- Radio, television and communication equipment and apparatus

- Medical, precision and optical instruments, watches and clocks

- Other transport equipment

- Furniture; other manufactured goods n.e.c.

- Recreational, cultural and sporting services

Other

- Products of forestry, logging and related services

- Fish and other fishing products; services incidental of fishing

- Coal and lignite; peat

- Crude petroleum and natural gas; services incidental to oil and gas extraction excluding surveying

- Uranium and thorium ores

- Metal ores

- Other mining and quarrying products

- Food products and beverages

- Tobacco products

- Textiles

- Wood and products of wood and cork (except furniture); articles of straw and plaiting materials

- Pulp, paper and paper products

- Printed matter and recorded media

- Coke, refined petroleum products and nuclear fuels 
- Chemicals, chemical products and man-made fibres

- Rubber and plastic products

- Other non-metallic mineral products

- Basic metals

- Fabricated metal products, except machinery and equipment

- Motor vehicles, trailers and semi-trailers

- Secondary raw materials

- Electrical energy, gas, steam and hot water

- Collected and purified water, distribution services of water

- Construction work

- Trade, maintenance and repair services of motor vehicles and motorcycles; retail sale of automotive fuel

- Wholesale trade and commission trade services, except of motor vehicles and motorcycles

- Financial intermediation services, except insurance and pension funding services

- Services auxiliary to financial intermediation

- Real estate services

- Renting services of machinery and equipment without operator and of personal and household goods

- Computer and related services

- Research and development services

- Other business services

- Public administration and defence services; compulsory social security services

- Sewage and refuse disposal services, sanitation and similar services

- Membership organisation services n.e.c.

- Other services

- Private households with employed persons

UK IO tables aggregation

Agriculture

- Products of agriculture, hunting and related services

Retail

- Retail trade services, except of motor vehicles and motorcycles; repair services of personal and household goods

Hotels and Restaurant

- Hotel and restaurant services

Freight and Public Transport

- Land transport; transport via pipeline services

Tourism and Travel

- Water transport services

- Air transport services
- Supporting and auxiliary transport services; travel agency services

Post and Telecom

- Post and telecommunication services

Insurance

- Insurance and pension funding services, except compulsory social security services

Education

- Education services

Health and Social Work

- Health and social work services

Non-Essential Items

- Wearing apparel; furs

- Leather and leather products

- Machinery and equipment n.e.c.

- Office machinery and computers

- Electrical machinery and apparatus n.e.c.

- Radio, television and communication equipment and apparatus

- Medical, precision and optical instruments, watches and clocks

- Other transport equipment

- Furniture; other manufactured goods n.e.c.

- Recreational, cultural and sporting services

Other

- Products of forestry, logging and related services

- Fish and other fishing products; services incidental of fishing

- Coal and lignite; peat

- Crude petroleum and natural gas; services incidental to oil and gas extraction excluding surveying

- Uranium and thorium ores

- Metal ores

- Other mining and quarrying products

- Food products and beverages

- Tobacco products

- Textiles

- Wood and products of wood and cork (except furniture); articles of straw and plaiting materials

- Pulp, paper and paper products

- Printed matter and recorded media

- Coke, refined petroleum products and nuclear fuels

- Chemicals, chemical products and man-made fibres

- Rubber and plastic products

- Other non-metallic mineral products

- Basic metals 
- Fabricated metal products, except machinery and equipment

- Motor vehicles, trailers and semi-trailers

- Secondary raw materials

- Electrical energy, gas, steam and hot water

- Collected and purified water, distribution services of water

- Construction work

- Trade, maintenance and repair services of motor vehicles and motorcycles; retail sale of automotive fuel

- Wholesale trade and commission trade services, except of motor vehicles and motorcycles

- Financial intermediation services, except insurance and pension funding services

- Services auxiliary to financial intermediation

- Real estate services

- Renting services of machinery and equipment without operator and of personal and household goods

- Computer and related services

- Research and development services

- Other business services

- Public administration and defence services; compulsory social security services

- Sewage and refuse disposal services, sanitation and similar services

- Membership organisation services n.e.c.

- Other services

- Private households with employed persons

\section{References}

1. Keogh-Brown, M.R., Smith, R.D.: The economic impact of SARS: how does the reality match the predictions. Health Policy 88, 110-120 (2008)

2. Mounier-Jack, S., Coker, R.J.: How prepared is Europe for pandemic influenza? Analysis of national plans. Lancet 367(99520), 1405-1411 (2006)

3. Beutels, P., Edmunds, W., Smith, R.: Partially wrong? Partial equilibrium and the economic analysis of infectious disease emergencies of international concern. Health Econ. 17(1), 13171322 (2008)

4. Sander, B., Nizam, A., Garrison, L.P., Postma, M.J., Halloran, M.E., Longini, M.S.: Economic evaluation of influenza pandemic mitigation strategies in the United States using a stochastic microsimulation transmission model. Value Health 12(2), 226-233 (2009)
5. DoH.: Pandemic influenza: a national framework for responding to an influenza pandemic. http://www.dh.gov.uk/en/Publications andstatistics/Publications/PublicationsPolicyAndGuidance/DH_ 0731(2007)

6. Woodall, J., Rowse, K.E.K., McDonald, J.C.: Age and Asian influenza. BMJ 29, 1316-1318 (1957)

7. Davis, L.E., Caldwell, G.G., Lynch, R.E., Bailey, R.E., Chin, T.D.Y.: Hong Kong influenza: the epidemiologic features of a high school family study analyzed and compared with a similar study during the 1957 Asian influenza epidemic 1970. Am. J. Epidemiol. 92, 240-247 (1970)

8. Ministry of Health.: Report on the Pandemic of Influenza, 191819, London: His Majesty's Stationery Office (1920)

9. DoH and HPIH \& SD.: UK Health Departments' Influenza Pandemic Contingency Plan. http://www.dh.gov.uk/en/Publications andstatistics/Publications/PublicationsPolicyAndGuidance/DH_ 4121(2005)

10. HHS.: HHS Pandemic Influenza Plan, in U.S. Department of Health and Human Services. http://www.hhs.gov/pandemicflu/ plan/ (2005)

11. HSE and DoH \& C.: (2007) National Pandemic Influenza Plan, in Health Services Executive and Department of Health and Children (Ireland). http://www.dohc.ie/publications/National_flu_ plan.html (2007)

12. Public Health Agency of Canada.: The Canadian Pandemic Influenza Plan For The Health Sector. http://www.phac-aspc.gc. ca/cpip-pclcpi/(2006)

13. Sadique, M.Z., Edmunds, W.J., Smith, R.D., et al.: Precautionary behavior in response to perceived threat of pandemic influenza. Emerg. Infect. Dis. 13(9), 1307-1313 (2007)

14. Ferguson, N.M., Cummings, D.A.T., Fraser, C., Cajka, J.C., Cooley, P.C., Burke, D.S.: Strategies for mitigating an influenza pandemic. Nature 44(27), 448-452 (2006)

15. Smith, R., et al.: Assessing the macroeconomic impact of a healthcare problem: the application of computable general equilibrium analysis to antimicrobial resistance. J. Health Econ. 24, 1055-1075 (2005)

16. McDonald, S., Thierfelder, K., Robinson, S.: Globe: A SAM Based Global CGE Model using GTAP Data, Economics Working Paper. US Naval Academy, Annapolis, MD (2007)

17. Rutten, M., Reed, G.: A comparative analysis of some policy options to reduce rationing in the UK's NHS: lessons from a general equilibrium model incorporating positive health effects. J. Health Econ. 28(1), 221-233 (2009)

18. Lofgren, H., Harris, R.L., Robinson, S.: A standard computable general equilibrium (CGE) model in GAMS. Microcomputers in policy research, vol. 5. IFPRI, Washington, DC (2002)

19. Mas-Colell, A., Whinston, M.D., Green, J.R.: Microeconomic theory. Oxford University Press, London (1995)

20. Varian, H.: Microeconomic analysis. Norton, New York (1992)

21. Dimaranan, B.V., McDougall, R.A., Hertel, T.W.: In: Dimaranan, B.V. (ed) Chapter 20. Behavioral parameters, in global trade, assistance, and production: the GTAP 6 database. Center for Global Trade Analysis, Purdue University (2006) 